Revista da Seção Judiciária do Rio de Janeiro

\title{
POLÍTICA, ESTADO E AUTORIDADES JURISDICIONAIS \\ NA IDADE MÉDIA \\ Entrevista com Maria Filomena Pinto da Costa Coelho
}

As entrevistas são oportunidades excepcionais para construir interlocuções, conhecer trajetórias acadêmicas e acompanhar um pouco melhor as caminhadas de pesquisa, ensino e extensão universitárias. Elas também nos servem para divulgar informações que muitas vezes não estão explicitadas nas folhas dos ensaios, artigos, capítulos e livros. As entrevistas reduzem um pouco a elisão das nossas próprias produções e fornecem um pequeno, mas muito significativo, vislumbre sobre 0 movimento da produção de conhecimento crítico.

É pensando nesse movimento de trajetórias acadêmicas, que convidamos para o Dossiê A Justiça na Idade Média a historiadora medievalista Maria Filomena Pinto da Costa Coelho. Atualmente, Maria Filomena é professora do Departamento de História e do Programa de Pós-Graduação em História da Universidade de Brasília (Unb). Além de ser bolsista de produtividade do CNPq, também é líder do grupo de pesquisa "De Corruptione" e co-coordenadora do Programa de Estudos Medievais da UnB. Nessa entrevista, o(a) leitor(a) poderá vislumbrar a reflexão sobre alguns dos principais temas investigados pela autora, especialmente os que correspondem ao poder e justiça, ao pluralismo jurídico e à questão da historicidade da corrupção na Península Ibérica Medieval. Com um olhar atento às relações entre presente e passado, e à nossa capacidade de comunicá-los a partir da perspectiva histórica e historiográfica, Filó, como carinhosamente a conhecemos, revela a criticidade necessária para construir um conhecimento capaz de (re)pensar continuamente os liames entre Direito, Estado e Sociedade.

Dra. Marta de Carvalho Silveira (UERJ)

Dr. Marcelo Pereira Lima (UFBA) 
Revista da Seção Judiciária do Rio de Janeiro

\section{Para iniciar nossa entrevista, gostaríamos que falasse um pouco sobre} sua trajetória acadêmica. Quando a Idade Média se tornou um período central nas suas investigações? Quais temas e enfoques guiaram suas atividades de ensino, pesquisa e extensão universitárias? Poderia discorrer quais projetos individuais e coletivos vem desenvolvendo nos últimos anos?

Iniciei o curso de História em 1982, no Instituto de Filosofia e Ciências Sociais (IFCS) da Universidade Federal do Rio de Janeiro (UFRJ) e terminei esse percurso na Universidade de Brasília (UnB), em 1987. Ao longo da graduação, fui descobrindo a Idade Média e percebendo o quanto o conhecimento desse passado longínquo funcionava como chave para formular boas questões sobre alguns problemas do presente. Assim, decidi me aprofundar nessa cronologia e acabei por fazer o doutorado na Universidad Complutense de Madrid, entre 1989 e 1993, tendo a sorte de contar com a orientação de dois medievalistas excepcionais: Reyna Pastor (CSIC) e Abílio Barbero de Aguilera (UCM). Posteriormente, para aprofundar meus estudos fiz dois estágios pós-doutorais. O primeiro, em 2002, na Faculdade de Direito da Universidade Nova de Lisboa, sob a supervisão de António Manuel Hespanha. O segundo, entre 2015-2016, na Scuola de Giurisprudenza da Università degli Studi di Firenze, sob a supervisão de Paolo Capellini e Pietro Costa. A partir de dezembro deste ano, iniciarei outro estágio pós-doutoral, desta vez na Faculdade de Direito da Universidade de São Paulo (USP), sob a supervisão de Samuel Barbosa. De minha experiência como historiadora formada no Brasil e da convivência na Espanha com os pesquisadores que faziam parte do Seminário dirigido por Reyna Pastor no CSIC firmou-se o hábito de interpretar o passado por meio de intensa reflexão problematizadora e crítica, do ponto de vista teórico e metodológico. Tal característica foi fortemente intensificada pelos estágios de pós-doutorado sempre realizados em estreito diálogo com historiadores e juristas que se destacam especialmente por seu aporte à renovação historiográfica. Então, mais do que 
Revista da Seção Judiciária do Rio de Janeiro

aprender conteúdos e informações sobre a Idade Média, minha preocupação centrou-se desde cedo em pensar na própria forma dos vestígios do passado e nos modos como os interpretamos. Nas minhas atividades acadêmicas, tento que 0 protagonismo recaia precisamente nesses aspectos, muito embora o faça recorrendo a determinados recortes da Idade Média que me interessam de perto. Creio que é muito importante para a nossa vida em sociedade, conhecer as diversas configurações do poder e dos modelos políticos que o legitimam e, sobretudo, evidenciar o caráter histórico e humano da arquitetura política, sua execução e as diferentes maneiras como é experimentada. Portanto, acabo por pesquisar sobre o poder público na Idade Média, atualmente com especial interesse em Portugal, entre os séculos XII e XIII. Decorrente desse enfoque, faço parte de alguns grupos de pesquisa, liderados por colegas da área do Direito, e, mais recentemente, eu e Leandro Rust criamos o De Corruptione, com o objetivo de estudar a corrupção na Idade Média, numa perspectiva política. Tenho ainda aproveitado uma iniciativa de trabalho de pesquisa em equipe, com colegas brasileiros, argentinos, costaricenses, chilenos e mexicanos, no âmbito da Rede Latino-americana de Estudos Medievais, com resultados promissores.

\section{As relações entre política e autoridade jurisdicional na Idade Média têm} sido um foco importante das suas pesquisas atuais, especialmente no que se refere à questão do pluralismo de poderes e jurisdições. Quais maneiras tradicionais e inovadoras de abordar esse tema no campo da História Política podem ser identificadas?

Comecei a me interessar pelo problema da jurisdição na Idade Média há alguns anos, ao comprovar a sua importância na trama do poder público. Basicamente, jurisdição é o poder de dizer a justiça, e em diferentes tipologias documentais é exatamente essa capacidade que é colocada na linha de frente nos conflitos entre poderosos que argumentam pela via jurídica. É claro que isso não impedia outras soluções, como as 
Revista da Seção Judiciária do Rio de Janeiro

de tipo bélico. Mas seguir o rastro das lógicas jurisdicionais permite aos historiadores acompanhar de perto os ingredientes e estratégias que ao longo do tempo vão dando forma e legitimando o poder público. Em termos historiográficos, qualquer tema que diga respeito à história do Estado, portanto do poder público, está muito marcado pelo próprio nascimento da História como disciplina moderna, como nacionalismo metódico. Assim, relativamente à Idade Média ibérica cristã, é muito comum que as abordagens associem de maneira exclusivista o poder público à monarquia e, a partir daí, passem a avaliar se o poder régio cumpria o papel que se espera do Estado no século XIX. Os resultados são quase sempre bastante anacrônicos, oscilando entre reis melhores e piores, numa espécie de 'escala weberiana' cujos valores são impossíveis de satisfazer. Na esteira da Nova História Política, têm se percebido algumas mudanças na maneira como se olha para o poder, com resultados bastante estimulantes. Entretanto, é preciso dizer que ainda há muito caminho a percorrer, uma vez que as abordagens institucionalistas e estatistas têm grande força, uma vez que, em grande medida, acabaram por ser naturalizadas até mesmo pelos(as) historiadores(as). Mas, como dizia, registram-se esforços para descobrir no passado outras formas de conceber e experimentar o poder público, com matrizes pluralistas - embora elitistas. Tais iniciativas têm possibilitado perceber diferentes configurações e dinâmicas relativamente ao próprio poder monárquico, mas, também, ao pontifício, ao episcopal, ao abacial, ao das corporações de ofícios, ao senhorial...

3. A História Política sobre a Idade Média ainda parece marcada pela aporia entre descentralização e centralização. Poderia expor as principais tendências desse debate? Quais perspectivas teórico-conceituais, metodológicas e historiográficas permitem superá-las? Trata-se de um falso problema? 
Revista da Seção Judiciária do Rio de Janeiro

Eu não diria que se trata de um falso problema, na medida em que essa dicotomia acabou por configurar uma das mais famosas formas da História política do ocidente. Outra, igualmente popular, é a oposição entre o mundo rural e o urbano. Aliás, a história escolar do Brasil é facilmente explicada, na longa duração, por meio dessas duas formas. Digamos que é um grande e real problema interpretativo. Portanto, será necessário enfrentá-lo de maneira adequada. Agora, se essa dicotomia centralização $X$ descentralização se colocava no tempo histórico ao qual os historiadores a aplicam é 'outra história'. Obviamente, trata-se de uma estratégia explicativa que empobrece a realidade política, sobretudo, devido ao seu caráter esquemático, reducionista, simplificador. 0 sucesso que esse antagonismo alcançou deve-se à personagem que o inspira: o Estado. Uma ideia de Estado que, como referi na resposta anterior, é filha de outra época, um tempo que se apresenta como o ápice da civilização ocidental. De tal modo o Estado, como medida de civilização, é sedutor, que a historiografia política se esforçou - e uma parte ainda se esforça para localizá-lo em épocas pretéritas, como uma espécie de selo de qualidade da sociedade em que ele supostamente se manifesta. Essa vinculação é fruto da história nacionalista, superada hoje em dia, principalmente, em suas formas ufanistas caricatas, porém, sobrevivente não mais como etnocentrismo descarado, mas sob aparência estatalista. Ou seja, a velha metanarrativa da nação sobrevive na metarrativa do Estado. É comum, na história do ocidente, se observar uma espécie de corrida rumo ao passado, para ver qual país conseguiu promover primeiro a "centralização" do poder político. Trata-se, assim, de uma questão muito própria da contemporaneidade, mas que os historiadores transportam para o passado mais distante, sem maiores reflexões. Para enfrentar esse problema, no que se refere à Idade Média, será necessário, por exemplo, considerar as maneiras pelas quais os atores históricos concebiam, exerciam e se submetiam aos poderes. Obviamente que, além de dizermos "como" isso acontecia, devemos também explicar os "porquês". Os vestígios documentais de que dispomos precisam ser interpretados em 
Revista da Seção Judiciária do Rio de Janeiro

plenitude, considerando todos os conteúdos e ambiguidades. Isso já vem sendo feito, com resultados que apontam para modelos e experiências políticas de grande dinamicidade e, sobretudo, para uma concepção de poder público legítimo que vai além da monarquia. Em termos conceituais é possível, sem abandonar nosso papel de intérpretes do passado e por meio de conceitos próprios da História, fazermos um esforço por desvendar os conteúdos que circunscreviam os conceitos construídos pelos atores históricos. A arte reside em entrelaçar os dois níveis, com as respectivas exigências. A metodologia terá que variar, de acordo com a tipologia documental.

\section{As formas como a corrupção foi percebida e classificada pelas} sociedades medievais variam conforme diversos marcadores sociais e históricos. Em se tratando da sociedade medieval portuguesa, gostaríamos que pontuasse as interconexões entre as formas de corrupção, as configurações institucionais dos poderes e o direito ibérico medieval. Poderia dar exemplos que ilustrassem essas relações?

O problema da corrupção é de grande atualidade, devido às implicações dramáticas que, hoje em dia, se traduzem, inclusive, em termos econômicos. Mas é fundamental percebermos que para boa parte dos especialistas, sobretudo dos historiadores, a corrupção está profundamente conectada à questão do Estado, ou seja à capacidade/incapacidade do poder para coibir os desvios e apropriações indevidas da coisa pública. Aliás, nesse sentido, tal capacidade faz mesmo parte dos critérios essenciais para determinar se um país pode ser classificado por entre as nações do primeiro mundo. Embora correndo o risco de ser demasiadamente ligeira, antes de entrar propriamente na resposta sobre a Idade Média, gostaria de ressaltar que o problema da corrupção nunca poderá ser enfrentado com propriedade enquanto não se compreender o quanto ele está vinculado ao modelo político que dá forma à sociedade. Do contrário, ficaremos eternamente caçando corruptos, que se sucedem como praga de gafanhotos. Estudar a corrupção na Idade Média - ou em outras 
Revista da Seção Judiciária do Rio de Janeiro

épocas históricas - permite perceber à distância quadros mais complexos, que colocam a questão em patamares que transcendem as leis, em termos de cumprimento/descumprimento, e os comportamentos individuais. Portanto, considerar diversas variáveis e tipologias documentais permite enxergar o peso do modelo político na fabricação da corrupção. Especificamente, sobre a sociedade portuguesa medieval, os marcadores sociais eram importantes, mas as acusações de corrupção atingiam, sobretudo, as camadas superiores. As formas da corrupção assemelham-se, em parte, às que reconhecemos hoje, como o suborno do agente público, mas havia uma abrangência maior que explicitamente incorporava as lógicas da teologia política, com resultados fortemente vinculados à filosofia clássica cristianizada. A perseguição aos comportamentos desviantes - laicos e religiosos - foi uma constante na Idade Média portuguesa, o que se pode comprovar facilmente pela profusão de leis sobre a matéria. Em termos da argumentação, as medidas são embasadas pelo princípio clássico de que não se pode desviar o bem público para satisfazer interesses particulares, o que prejudicaria o bem comum. Então, há um aspecto a ser sublinhado: havia - ao contrário do que se afirma com frequência uma noção da diferença entre o público e o privado. Obviamente, que tal diferença não corresponde aos padrões de exigência de uma sociedade democrática, como pretende ser a nossa. E é justamente aqui que reside o elemento político fundamental: o modelo de sociedade. Ora, a sociedade portuguesa medieval foi concebida com base em um modelo profundamente hierarquizado e assentado nos privilégios das ordens superiores, ou seja, um modelo elitista. Dessa forma, a elite e suas ações tendem a se identificar e, ao mesmo tempo, a dar identidade à coisa pública. Tal ambiguidade é essencial, em termos políticos, pois fornece a elasticidade argumentativa necessária às disputas pelo poder que serão, quase sempre, resolvidas no campo da legitimidade/ilegitimidade, por conteúdos traduzidos como virtude/corrupção. É claro que no próprio cenário político as batalhas discursivas revelam situações extremamente cambiantes em que um lado/bando acusa o outro 
Revista da Seção Judiciária do Rio de Janeiro

de corrupto, e ambos com propriedade argumentativa no campo jurídico, moral etc. As disputas são extremamente acirradas em torno do poder de dizer o que é virtude, o que é corrupção, quem é virtuoso, quem é corrupto.

\section{As universidades brasileiras têm sido chamadas a desenvolver projetos} articulados ao ensino, pesquisa e extensão. Levando em conta o papel social e político das universidades, como as pesquisas sobre o Direito Medieval podem contribuir para a integração crítica entre essas três dimensões da vida acadêmica?

O estudo do direito na Idade Média possibilita conhecer um vasto período da História em que se foram construindo importantes alicerces que ainda hoje sustentam a sociedade ocidental. Entretanto, tal possibilidade depende muito da maneira como esse estudo for realizado. É comum que a História do Direito seja considerada a partir de perspectivas oriundas de uma certa maneira de conceber o papel do Estado e seu aparato legislativo e judicial. Refiro-me, uma vez mais, ao século XIX. Entender que o Código de Hamurabi prefigura as Constituições da contemporaneidade é passar um rodo uniformizador pela fieira dos séculos, empobrecendo a História. Ao mesmo tempo, alimenta certa visão romântica sobre a capacidade mágica de que os corpora legais teriam para moldar as sociedades humanas. Há, entretanto, outra forma de estudar o direito, muito mais profícua, e muito mais histórica, que permite perceber a sua dimensão política, como resultado da escolha - daqueles que podiam escolher - e da submissão - daqueles que não podiam escolher. O mundo do direito deve ser estudado como produto histórico de seres humanos, e não como um destino manifesto inquestionável. Nesse sentido, e dada a importância da questão, esses estudos precisam ser contemplados pelo tripé ensino-pesquisa-extensão.

\section{Os diversos debates sobre a chamada História Pública (Public History) têm ganhado visibilidade e dizibilidade na historiografia brasileira nos}


Revista da Seção Judiciária do Rio de Janeiro

últimos anos. Isso se nota na profusão de seminários, simpósios, colóquios, cursos, publicações e nas redes de colaboração nacional e internacional. Seus projetos coletivos e individuais contemplam essa modalidade de história, especialmente quando se leva em conta o ensino de história medieval para um público mais amplo?

Tenho me esforçado nesse sentido, muito embora ainda necessite me esforçar muito mais. Penso que a demanda é desafiadora para a academia, inclusive, na medida em que acaba por se misturar ao clima de excesso de exposição e de opinião que a internet possibilita. Em termos do conhecimento científico, é importante dizer claramente que nem tudo é válido, ou seja, nem tudo tem o mesmo valor. Estamos atravessando uma época perigosa para o conhecimento, em que se tenta propagar uma ideia de que a mera opinião e a mera vontade são equivalentes às conclusões resultantes de estudos levados a cabo com critérios metodológicos transparentes e auditáveis. Assim, relativamente ao conhecimento do passado, deve-se aplicar o mesmo cuidado. Isso não quer dizer que se deva restringir o acesso ao conhecimento histórico, para preservá-lo de influências nefastas. Ao contrário, creio que é justamente por meio do alargamento das discussões sobre a interpretação do passado que se pode 'proteger' a História de manipulações. É necessário levar a cabo uma profunda alfabetização histórica do público em geral, coisa que não tem nada a ver com aprender datas e fatos. Trata-se de conhecer e discutir como se constroem as memórias da sociedade e do poder, as implicações dos critérios de seleção dos vestígios do passado a preservar, e as maneiras de interpretá-los. Isso ampliará a nossa capacidade de conhecer o passado, por meio de diferentes perspectivas e vozes, sempre como resultado de um conhecimento com bases sólidas, mas plural. A circulação do conhecimento, com significado histórico - inclusive do tempo presente - um saber muito mais horizontalizado, que não se desgarra de parâmetros científicos. É um grande desafio, porém, já está em marcha. E, como dizia Antonio Machado "se hace camino al andar...". 